\title{
A new ethanol biosensor based on polyfluorene-g-poly(ethylene glycol) and multiwalled carbon nanotubes
}

\author{
Siddika Aybuke Bekmezci ${ }^{\mathrm{a}}$, Saniye Soylemez ${ }^{\mathrm{b}, *}$, Gorkem Yilmaz $^{\mathrm{c}}$, Yasemin A. Udum ${ }^{\mathrm{d}}$, \\ Yusuf Yagci ${ }^{\mathrm{c}, *}$, Levent Toppare ${ }^{\mathrm{a}, \mathrm{e}, \mathrm{f}, \mathrm{g}, *}$ \\ a Department of Chemistry, Middle East Technical University, Ankara 06800, Turkey \\ ${ }^{\mathrm{b}}$ Department of Chemistry, Ordu University, Ordu 52200, Turkey \\ ${ }^{\mathrm{c}}$ Department of Chemistry, Istanbul Technical University, Istanbul 34469 Turkey \\ ${ }^{\mathrm{d}}$ Gazi University, Technical Sciences Vocational School, Ankara 06374, Turkey \\ ${ }^{\mathrm{e}}$ Department of Biotechnology, Middle East Technical University, Ankara 06800, Turkey \\ ${ }^{\mathrm{f}}$ Department of Polymer Science and Technology, Middle East Technical University, Ankara 06800, Turkey \\ ${ }^{\mathrm{g}}$ The Center for Solar Energy Research and Application (GUNAM), Middle East Technical University, Ankara 06800, Turkey
}

\section{A R T I C L E I N F O}

\section{Keywords:}

PEG

Conjugated polymer

Polyfluorene

MWCNTs

Amperometric ethanol biosensor

\begin{abstract}
A B S T R A C T
Functionalization of the conjugated polymers has gained considerable interest in the biomedical engineering and biosensing applications as distinct properties can be imparted to the corresponding pristine analogues. In the present work, we report a novel sensing platform for the quantification of ethanol through a macromolecular design involving polyfluorene-g-poly(ethylene glycol) (PF-g-PEG) and multiwalled carbon nanotubes (MWCNTs). First, poly(ethylene glycol) with fluorene functionality (PEG-FL) was synthesized with a one-step procedure and characterized. The nanotube modified electrodes were then used as working electrodes for the electropolymerization of PEG-FL macromonomer to form PF- $g$-PEG films on the electrode surface. Finally, alcohol oxidase enzyme was immobilized on the modified surfaces. Similar devices without MWCNTs or PF- $g$-PEG were prepared and compared. Sensor properties for selective ethanol detection were investigated and it was found that PF-g-PEG modified MWCNTs exhibited the highest sensing ability. The potential practical application of the fabricated biosensor is demonstrated in alcoholic drinks for the analysis of ethanol contents.
\end{abstract}

\section{Introduction}

A growing effect of sensor technology has a significant impact on human daily life. Significant advances have been made in this area since the biosensing platforms present several advantages including minimal costs, simplicity and has the potential for real-time monitoring. Traditionally, the monitoring of ethanol content in beverages is carried out using different techniques such as refractometry, densitometry, redox titration or gas chromatography [1]. Nevertheless, the complexity and low response time of these methods prevents their use for continuous monitoring. In view of these factors, electrochemical approaches are the most promising candidate technologies and bring great innovation over the traditional methods. Electrochemical biosensors have attracted great attention in the area of food quality via providing highly sensitive and fast monitoring ability during the process [2-5]. Ethanol detection plays an important role in clinical analysis and food industries. Economic, simple and accurate measurements are required in order to detect ethanol amount in a body fluid such as serum, urine, sweat and to check fermentation process in beverages. Electrochemical biosensor for ethanol sensing can be constructed using alcohol oxidase (AOx) enzyme. AOx, as a model enzyme, that catalyzes the oxidation of short chain, low molecular weight aliphatic alcohols to their corresponding aldehydes [6]. Literature is highly progressed into the detection of ethanol content in beverages using different biosensing architectures. For the improvement in the alcohol oxidizing enzymes in the sensor surfaces, different biocompatible materials and immobilization strategies were explored and summarized in the literature [7]. Recently a third generation alcohol biosensor was fabricated using ferrocene modified AOx on the MWCNTs based nanocomposite electrode surface with sol-gel chitosan film coated horseradish peroxidase (HRP) [8]. Such a sensor was successfully used for ethanol detection in commercial samples. In another work, Chinnadayyala et al. utilized an electrochemical biosensor creating AOx-AuNPs conjugate for ethanol quantification amperometrically [9]. To fabricate this sensor, AuNPs-AOx conjugate was encapsulated with polyaniline (PANI) and then, it was

\footnotetext{
* Corresponding authors at: Ordu University, Department of Chemistry, 52200 Ordu, Turkey (S. Soylemez).

E-mail addresses: saniyesoylemez@odu.edu.tr (S. Soylemez), yusuf@itu.edu.tr (Y. Yagci), toppare@metu.edu.tr (L. Toppare).
} 


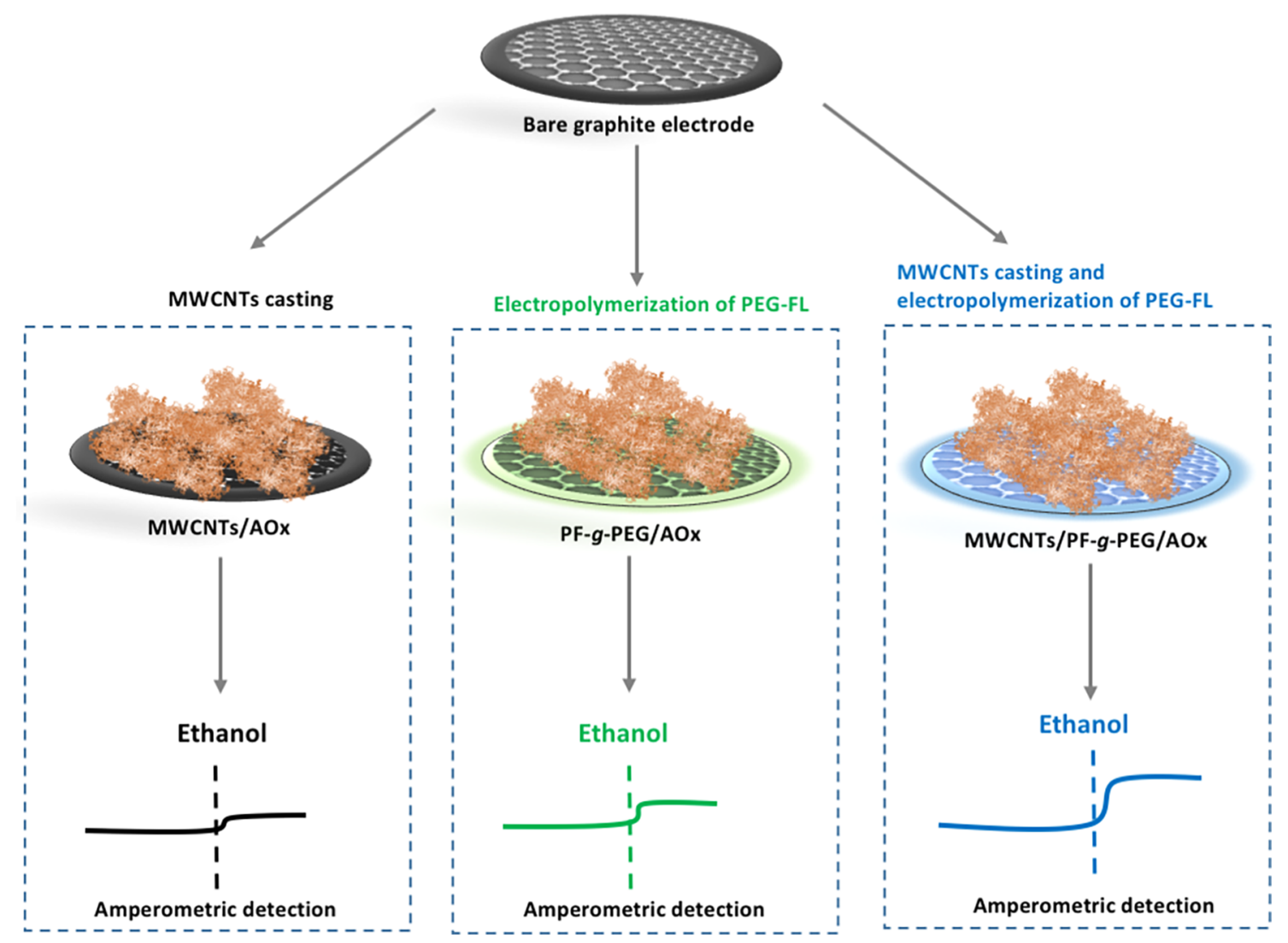

Scheme 1. Schematic representation for the construction pathway of the biosensors.

stabilized on a glassy carbon electrode (GCE) by chitosan-Nafion mixture. Moreover, alcohol oxidase (AOx) was immobilized on multiwalled carbon nanotubes-Nafion ${ }^{\circledR}$ (MWCNT-Nf) matrix and encapsulated with polyethylenimine (PEI) on gold electrode (AuE) to fabricate ethanol biosensor [10]. Even such systems detect ethanol properly, both complicated methods and long electrode preparation process of them clearly shows the need for new systems. By this motivation, herein the main idea is to construct an ethanol biosensor with high selectivity toward its analyte and easy modification steps of the transducer.

The primary focus of the biosensing layer construction is to choose proper materials to construct robust and highly suitable matrices for biomolecules. Conjugated polymers (CPs) are good candidates for such applications since they have the ability to improve charge transfer, stability and biomolecule localization during enzyme immobilization process $[11,12]$. Speed of sensing, fast response and certainty are the additional benefits of conjugated polymers based sensors. Among various conjugated polymers, the fluorene class of conjugated polymers combines several advantages that make them well-suited contenders for applications in organic optoelectronic devices and sensors [13]. Previously, visual sensing of avidin was successfully accomplished using polyfluorene based design [12]. In another example, phosphate was determined using fluorescent biosensor composed of polyfluorene-liposomal nanoparticles coupled with alkaline phosphatase [14]. Especially the functionalized fluorene derivatives have attracted great attention. The methylene bridge (C9 position) in fluorene structure provides an easy modification or functionalization. For instance, an amino acid side chain functionalized polyfluorene derivative poly[N-(9-fluorenylmethoxycarbonyl)-glycine] (P9FG) was synthesized and used in sensing applications [15]. Fluorene derivatives have also been prepared with poly(ethylene glycol) (PEG) via attaching to the carboxylic acid containing 9-position of fluorene in order to enhance the sensing properties of the biosensor. Because of the hydrophilic nature of the PEG, the surface grafted with PF-g-PEG film can easily interact with enzyme molecules in order to produce desired biosensing device [16]. Moreover, nanomaterials combined with polymers are the most preferable combinations for the achievement of precise targeting. Such combination is employed in the development of electrochemical biosensors due to their unique electrocatalytic properties [17]. Carbon nanotubes (CNTs) provide fast electron transfer between biorecognition elements and transducers arising from their great electrical and mechanical properties. Since carbon nanotubes have electrochemical stability and high surface area, they are frequently incorporated as sensing elements for amperometric biosensors [18].

In biosensor fabrication, the method of localization of the desired biomolecules onto an electroactive electrode is generally the first and major concern. To create the best sensing ability sensor devices, herein poly(ethylene glycol) with fluorene functionality (PEG-FL) macromonomer was synthesized and its electrochemical polymerization through the fluorene-backbone was achieved. Before polymerization of the monomer, the electrode surfaces were modified with multiwall carbon nanotubes (MWCNTs) in order to prepare suitable matrices and enhance charge transfer ability. After electropolymerization step, alcohol oxidase (AOx) was immobilized onto the polymer modified electrode surface using glutaraldehyde (GA) as a cross linking agent. Amperometric measurements were performed in $50 \mathrm{mM}$ phosphate buffer solutions at $\mathrm{pH} 7.0$ under the constant potential. The surface properties of the biosensor were evaluated using cyclic voltammetry (CV) and scanning electron microscopy (SEM) techniques. Finally, constructed biosensor was tested in various beverages to detect ethanol content, successfully. A typical sensor design is summarized in Scheme 1.

\section{Experimental}

\subsection{Materials and apparatus}

Alcohol oxidase (AOx,E.C. 1.1.3.13) (35 Units/mg protein) from Pichia pastoris, glutaraldehyde ( $\% 50 \mathrm{wt}$ in $\mathrm{H}_{2} \mathrm{O}$ ), multi- walled carbon 
<smiles>COCCOCCOCCOCCOC(=O)C1c2ccccc2-c2ccccc21</smiles>

(Yield: $79.8 \%$ )
Scheme 2. Synthesis of fluorene functional poly (ethylene glycol) (PEG-FL).

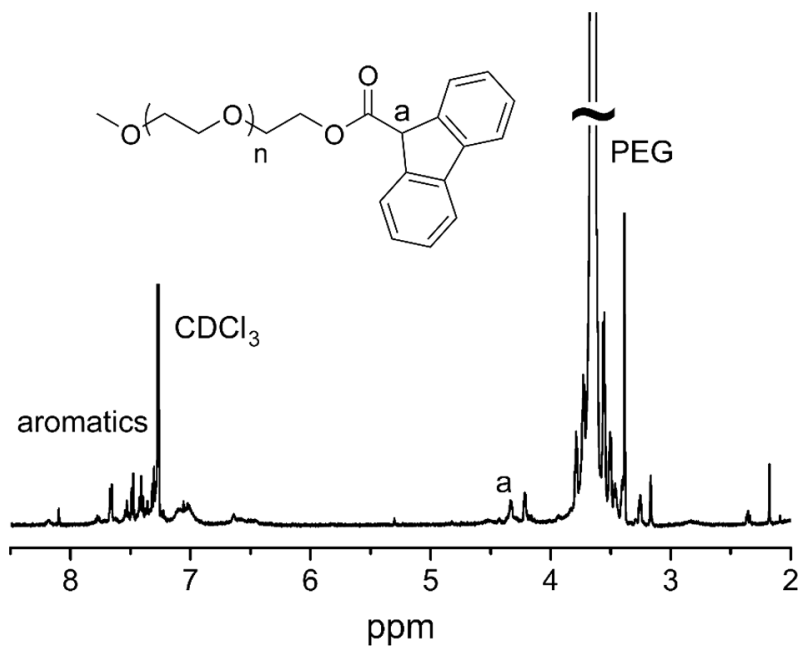

Fig. 1. ${ }^{1} \mathrm{H}$ NMR spectrum of PEG-FL.

nanotube (carbon > 95\%, O.D. $\times$ L 6-9 $\mathrm{nm} \times 5 \mu \mathrm{m}$ ) and boron trifluoride diethyl etherate $\left(\mathrm{BF}_{3} \cdot \mathrm{O}\left(\mathrm{C}_{2} \mathrm{H}_{5}\right)_{2}\right)$ were obtained from SigmaAldrich. Dichloromethane (DCM), acetonitrile (ACN), ethanol (as a substrate), methanol and 2-propanol were purchased from Merck (Darmstadt, Germany). Poly(ethylene glycol) monomethyl ether ((PEG) $M_{\mathrm{n}} \sim 2000$, Aldrich) $N, \quad N$-dicyclohexylcarbodiimide (DCC, 99\%, Sigma-Aldrich) and 4-dimethylaminopyridine (DMAP, 99\%, SigmaAldrich) were used as received. All chemicals were of analytical reagent grade.

\subsubsection{Instrumentation}

Electropolymerization was achieved with GAMRY Reference 600 (GAMRY Instruments Inc., Pennsylvania, USA). A PalmSens potentiostat (Palm Instruments, Houten, The Netherlands) was used for amperometric measurements. Both electrochemical and amperometric experiments were carried out with a conventional three-electrode system with the enzyme electrode as the working electrode, a platinum wire as the counter electrode and a silver wire as the pseudo reference electrode. As a bare transducer surface a graphite electrode $(3.0 \mathrm{~mm}$ diameter) was used as the working electrode, platinum electrode and silver wire were used as the counter and reference electrodes, respectively. These electrodes were combined to create three electrode system. Three repeatable signals were used to evaluate amperometric measurements and reported as $\pm \mathrm{SD}$. For surface morphology of biosensor, scanning electron microscope (SEM) (JEOL JSM-6400 model) was used. ${ }^{1} \mathrm{H}$ NMR spectra were recorded using an Agilent VNMRS $500 \mathrm{MHz}$ (Santa Clara, CA, USA) and chemical shifts were recorded in ppm using tetramethylsilane as the internal standard All measurements were performed at room temperature.

\subsection{Synthesis of fluorene functional poly(ethylene glycol) (PEG-FL)}

In a round bottom flask equipped with a magnetic stirrer, fluorene9-carboxylic acid (2.5 eq), PEG $\left(M_{\mathrm{n}}: 2000 \mathrm{~g} / \mathrm{mol}, 1.0 \mathrm{eq}\right)$ and DMAP (1.0 eq) was added and dissolved in $\mathrm{CH}_{2} \mathrm{Cl}_{2}$. Next, $N, N^{\prime}-$ dicyclohexylcarbodiimide (1 eq) dissolved in $\mathrm{CH}_{2} \mathrm{Cl}_{2}$ was slowly added to the mixture. The reaction mixture was allowed to stir for $24 \mathrm{~h}$. The precipitate was filtered off and the residue was twice precipitated into cold diethyl ether. The precipitate was filtered off and the residue was twice precipitated into cold diethyl ether to give the yellowish product (Scheme 2) (Yield was found to be $79.8 \%$ as determined by ${ }^{1} \mathrm{H}$ NMR) analysis by comparing the aromatic protons og fluorene group with the protons of PEG chain (Fig. 1).

\subsection{Biosensor fabrication procedure and amperometric detection of ethanol}

Graphite electrodes were polished before each experiment with an emery paper, then rinsed thoroughly with distilled water. For the preparation of a MWCNTs/PF-g-PEG/AOx electrode, the following procedure was applied: $0.25 \mathrm{mg}$ of MWCNT was dispersed in $5.0 \mathrm{~mL}$ of DMF by ultrasonication for $1 \mathrm{~h}$ and then $10 \mu \mathrm{L}$ of the corresponding solution was cast on the surface of previously cleaned graphite electrode. The carbon nanotube modified electrode was allowed to dry at room temperature for $1 \mathrm{~h}$. The nanotube modified electrodes were then used as a working electrode for electropolymerization process. PEG-FL macromonomer $(5 \mathrm{mg} / \mathrm{mL})$ was polymerized in the presence of ACN:DCM (95:5) in $0.1 \mathrm{M} \mathrm{NaClO}_{4} / \mathrm{LiClO}_{4}$ containing borontrifluoride diethyletherate (BFEE) by scanning between $0.0 \mathrm{~V}$ and $+1.8 \mathrm{~V}$ (scan rate: $100 \mathrm{mV} / \mathrm{s}$ ). After this step, polymer modified electrodes were rinsed with distilled water. For enzyme immobilization step, $4.0 \mu \mathrm{L}$ of AOx solution was cast on the proposed electrode surface and glutaraldehyde (GA) $\left(4.0 \mu \mathrm{L}, \% 1\right.$ in $\left.\mathrm{H}_{2} \mathrm{O}\right)$ was added on the electrode surface to obtain final biosensor for ethanol sensing. The prepared electrode was left to dry for $2 \mathrm{~h}$ at room temperature. Before using it, the electrodes were washed with distilled water to get rid of unbound enzyme molecules.

To compare optimum biosensor performance with the unmodified ones, following procedures were followed: MWCNTs/AOx electrode was prepared using $0.25 \mathrm{mg}$ MWCNT/DMF solution. $10 \mu \mathrm{L}$ of the corresponding solution was cast on the surface of the bare graphite electrode and left for $1 \mathrm{~h}$ for drying. After the cleaning procedure of the electrodes with distilled water, the enzyme immobilization was achieved using the same procedure with the optimum sensor preparation. To construct PF-g-PEG/AOx sensing platform, the bare graphite electrodes were modified with the polymer without using carbon nanotubes. The following preparation protocol was the same with the electropolymerization step of the optimum sensor. Then, enzyme molecules were immobilized on the pristine polymer modified surfaces to analyze ethanol content in beverages. All enzyme electrodes were cleaned with distilled water and stored at $4{ }^{\circ} \mathrm{C}$ in dry state unless otherwise reported.

Three electrode system; MWCNTs/PF-g-PEG AOx (WE), a silver wire pseudo-reference electrode (RE) and a platinum wire electrode (CE) was constructed. These electrodes were connected to a potentiostat (PalmSens, produced by Palm Instrument, Netherland). The electrodes were inserted into the cells $(10 \mathrm{~mL})$ for amperometric measurements. A smaller cell $(2 \mathrm{~mL})$ was preferred during the electrochemical measurements. Amperometric measurements experiments were achieved under mild stirring. Response signals of AOx biosensor were monitored at $-0.7 \mathrm{~V}$ by following the oxygen consumption stemming from the oxidation of short chain, low molecular weight aliphatic alcohols by the AOx. 


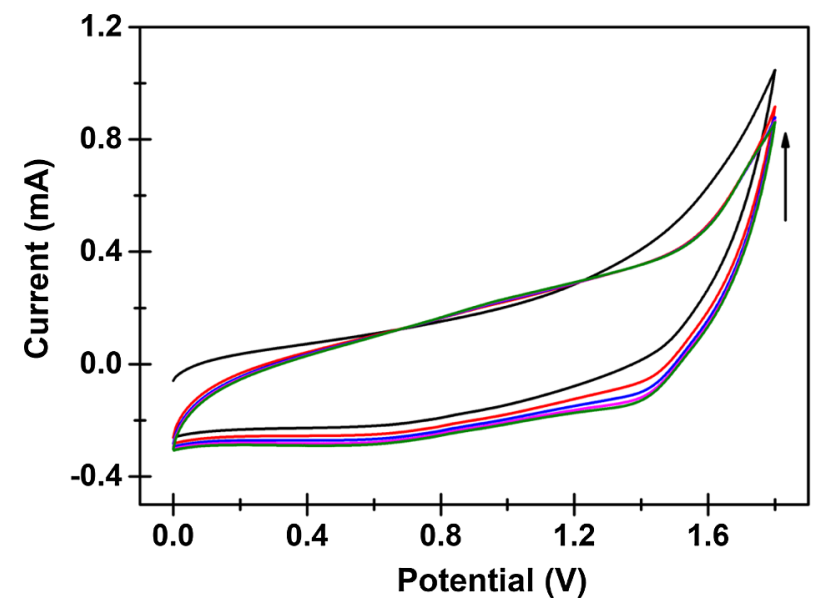

Fig. 2. Cyclic voltammograms for polymerization of PEG-FL in $0.1 \mathrm{M} \mathrm{NaClO}_{4}$ / $\mathrm{LiClO}_{4} / \mathrm{ACN} / \mathrm{DCM} / \mathrm{BFEE}$ system at a scan rate of $100 \mathrm{mVs}^{-1}$ on graphite (up to 5 cycles).

\section{Results and discussion}

\subsection{Electropolymerization of PEG-FL and optimization studies of the proposed sensor}

Electrochemical polymerization was performed on MWCNTs coated electrode surface using cyclic voltammetry technique. PEG-FL macromonomer $(5 \mathrm{mg})$ was dissolved in $1 \mathrm{~mL}$ of ACN:DCM (95:5) in $0.1 \mathrm{M}$ $\mathrm{NaClO}_{4} / \mathrm{LiClO}_{4} / \mathrm{BFEE}$ electrolyte-solvent system by scanning between $0.0 \mathrm{~V}$ and $+1.8 \mathrm{~V}$ potential. The redox behaviors of the polymer were shown in Fig. 2.

All ingredients of the MWCNTs/PF-g-PEG/AOx biosensor was optimized to find out the best sensing ability sensor. First of all, optimum cycle number of polymer (PF-g-PEG) was determined from amperometric measurements at varying cycle numbers from 10 cycles to 40 cycles.

Average currents at each cycle obtained from amperograms were reported as a function of cycle number (Fig. 3A). The highest current appears at a cycle number of 30. Since very thick or thin polymeric layers may not allocate the enzyme molecules properly, herein the cycle number of the polymer should be 30 cycles to create a great architecture for enzyme localization. It corresponds to the good enzymatic reaction between the created surface and biomolecules. At the following optimization step, effect of amount of AOx enzyme was investigated to obtain optimum enzyme amount. Different amounts of the enzyme ( $0.5 \mu \mathrm{L}, 2 \mu \mathrm{L}, 4 \mu \mathrm{L}, 6 \mu \mathrm{L}$ and $8 \mu \mathrm{L}$ AOx) were immobilized on the MWCNTs/PF-g-PEG surfaces by keeping other parameters constant. The enzyme electrode prepared with $4 \mu \mathrm{L}$ AOx can reach a steady state current quickly within $5 \mathrm{~s}$. This is much faster than the electrodes prepared with 6 and $8 \mu \mathrm{L}$ of enzyme electrodes. Such a low response can be attributed to the low diffusion of the substrate molecule in the thin and huge enzymatic surface. Hence, $4 \mu \mathrm{L} \mathrm{AOx} \mathrm{(6.4} \mathrm{U}$ ) was selected as the optimum amount and used for further experiments (Fig. 3C). Finally, MWCNTs/PF-g-PEG/AOx biosensor was examined to show the possible effect of $\mathrm{pH}$ on the response of AOx based biosensors to ethanol. The prepared electrodes were used for current measurements at a potential of $-0.7 \mathrm{~V}$ (like other optimization experiments) in solutions containing $50 \mathrm{mM}$ buffers having different $\mathrm{pH}(3.0,5.0,7.0,8.0$ and 10.0). A current vs pH plot was drawn in (Fig. 3B). The maximum responses were recorded in $\mathrm{pH} 7.0$ medium. Thus, subsequent measurements were carried out at this $\mathrm{pH}$ for $\mathrm{AOx}$ based biosensor.

\subsection{Electrochemical and surface characterization of the biosensor}

Randless-Sevcik equation [19] can be utilized to evaluate the effective surface areas of the modified surfaces (bare graphite electrode,
MWCNTs/PF- $g$-PEG and MWCNTs/PF- $g$-PEG/AOx electrodes). The related experiments were carried out in $5.0 \mathrm{mM} \mathrm{Fe}(\mathrm{CN})_{6}{ }^{3-/ 4-}$ solution containing $0.1 \mathrm{M} \mathrm{KCl}$ to investigate the electroactive surface area after depositing the corresponding layers (Fig. 4). Cyclic voltammograms were obtained at a scan rate of $100 \mathrm{mV} / \mathrm{s}$ using the three electrolyte systems. The average values were calculated to be $0.43 \mathrm{~cm}^{2}$ for the MWCNTs/PF- $g$-PEG and $0.193 \mathrm{~cm}^{2}$ for the MWCNTs/PF-g-PEG/AOx. The presence of the insulating biomolecule on the polymer and nanotube modified surfaces decreases the electroactivity of the corresponding electrode which results in smaller electroactive surface area than the others.

Morphological surface changes of the electrodes were evaluated using scanning electron microscopy (SEM) (Fig. 5). The surface of MWCNTs/PF-g-PEG film is rather smooth and homogenous. Both typical structures of multiwalled carbon nanotubes and polymer can be seen in Fig. 5B. The addition of biomolecules onto the MWCNTs/PF-gPEG film surface (Fig. 5C) brought uniform and different surface features. This homogenous surface increased the amperometric ability of the biosensor.

\subsection{Analytical feature of the ethanol biosensor}

Analytical statement of the designed biosensor was carried out by amperometric ethanol analysis. Typical amperometric results can be seen in Fig. 6A and B. The stable currents were obtained after each addition of ethanol against concentration. The MWCNTs/PF- $g$-PEG/ AOx was capable to detect ethanol linearly up to $5.95 \mathrm{mM}$ with a sensitivity of $7.99 \mu \mathrm{A} \mathrm{mM}^{-1} \mathrm{~cm}^{-2}$, using data obtained from a calibration curve equal to $\mathrm{y}=0.4818 \mathrm{x}+0.3478$ which is $\mathrm{R}^{2}=0.999$, where $\mathrm{y}$ and $\mathrm{x}$ indicate, respectively, the current expressed in $\mu \mathrm{A}$ and the ethanol concentration in $\mathrm{mM}$. The sensor detects ethanol in the linear range between 0.0085 and $5.95 \mathrm{mM}$. The limit of detection of the ethanol biosensor was also found to be as $0.11 \mathrm{mM}$. Additionally, repeatability of the biosensor was tested by taking ten sequential signals. The related signals were recorded and standard deviation (SD) and relative standard deviation (RSD) were calculated as \pm 0.09 and $3.91 \%$, respectively. The biosensor response was stable for 10 successive measurements completed in a period of $1 \mathrm{~h}$ and retained $95 \%$ of the original response even after one day when stored at $4{ }^{\circ} \mathrm{C}$. The proposed sensor showed quite good stability for repetitive uses.

The results obtained for the optimum sensing system was compared with the previously reported studies in Table 1 . Moreover, the results were also compared with the biosensors prepared with pristine materials. As summarized in Table 1, the best results were obtained with the optimum sensing layer (MWCNTs/ PF-g-PEG/AOx). Multiwalled carbon nanotubes and conjugated polymers are being used very often in the preparation of enzymatic biosensors due to their ability to create wonderful surface properties. Such a surface has the ability to facilitate great immobilization of biomolecule, and to ease the charge transfer. However, sometimes it is not sufficient to create a great architecture with the pristine ones due to the difficulty to create suitable surface characteristics for enzyme localization. At this point, these two materials can be combined to obtain good sensing ability sensing layers.

Herein, the effect of pristine PF-g-PEG polymer and MWCNTs was also investigated in our work. Improvements have been observed on performance of the biosensors created by good interactions of the nanotubes and the polymer. Fig. $6 \mathrm{~A}$ shows the amperometric results of the biosensors with pristine ones in $50 \mathrm{mM} \mathrm{pH} \mathrm{7.0} \mathrm{PBS.} \mathrm{The} \mathrm{maximum}$ signals were recorded by MWCNTs/PF- $g$-PEG/AOx. The optimum biosensor exhibited a series of good properties: high sensitivity, short response time and remarkable long-term stability during amperometric measurements. Using carbon nanotubes and functionalized conjugated polymers as structural components for the films is of great interest. Although they possess a unique surface of electrodes for sensor applications, it is not sufficient to get a great surface when they used separately. At this point, one possible and effective way of improving the 

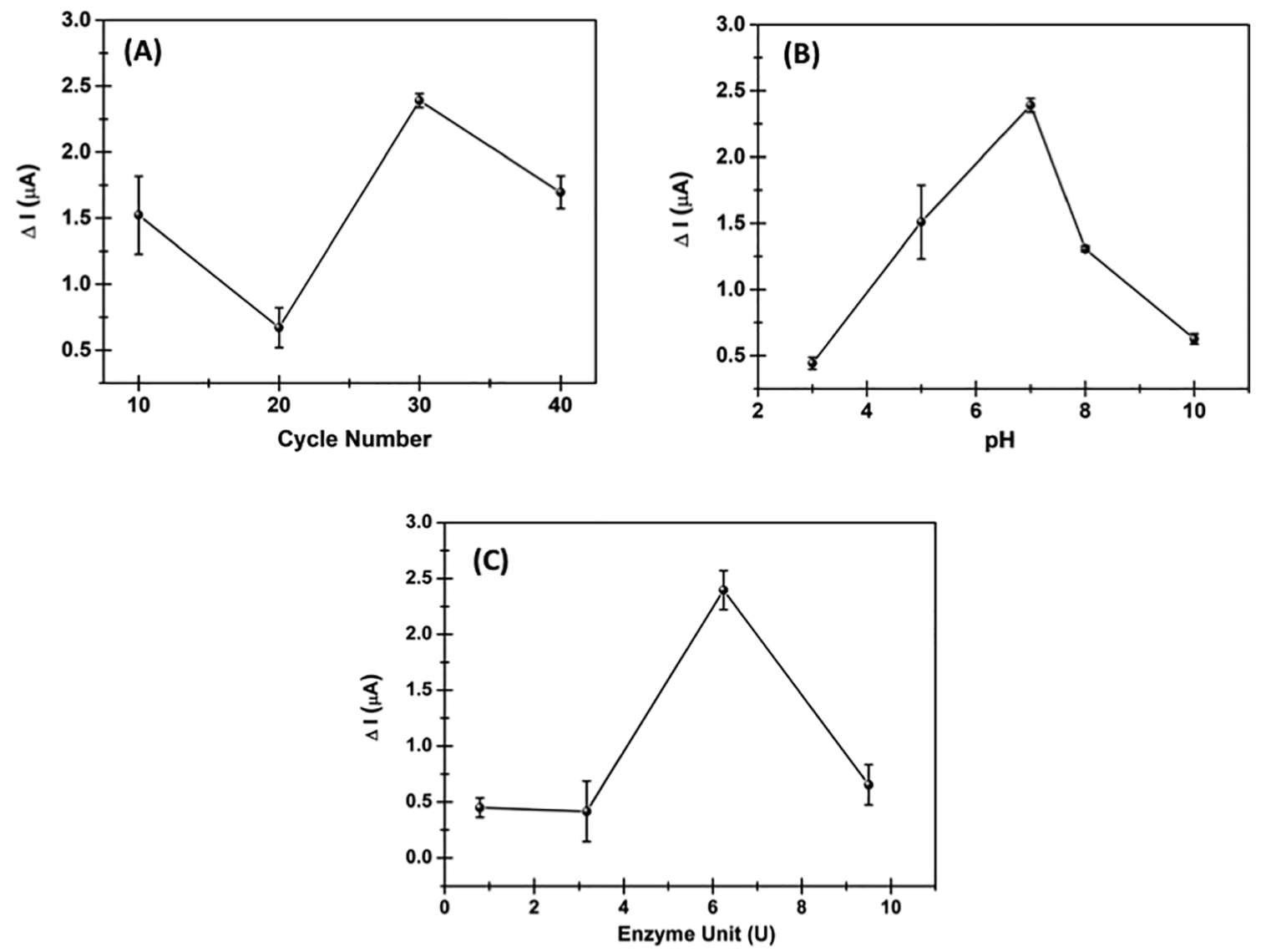

Fig. 3. Optimization studies ((A) cycle number, (B) pH and (C) enzyme unite) to obtain the best sensing platform.

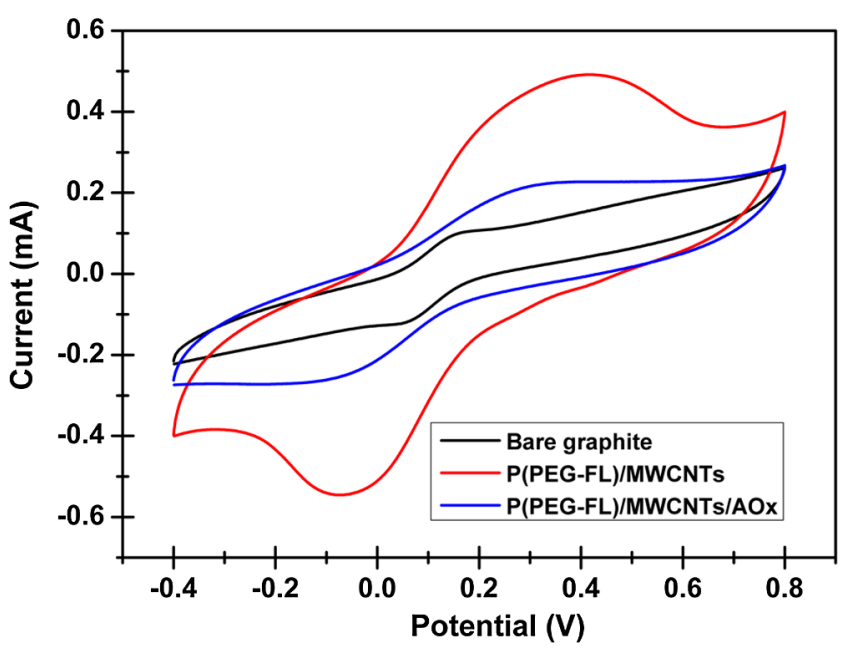

Fig. 4. Cyclic voltammogram of bare graphite electrode, MWCNTs/PF-g-PEG and MWCNTs/PF-g-PEG/AOx in $5 \mathrm{mM} \mathrm{Fe}(\mathrm{CN})_{6}{ }^{3-/ 4-}$ containing $0.1 \mathrm{M} \mathrm{KCl}$ and pH 7.0 PBS.

activity of an immobilized enzyme is to combine functional polymers with carbon nanotubes that are more practical in biosensor experiments. Since carbon nanotubes can be employed as a component for the construction of reliable and robust electrochemical biosensors they are considered as highly suitable materials to construct biocompatible platforms in biotechnological applications [20]. They have also several advantages such as good chemical and mechanical properties, good electrical conductivity, high surface area and create fast response biosensing systems. These unique properties make them extremely attractive for the design of electrochemical sensing devices, especially in bio-sensing systems. All of these features helped for increase in the biosensor signal (Fig. 6B). Relatively low responses were created with the pristine polymer film (Fig. 6B). In addition to this, such a sensor showed long response time compared to the biosensor prepared with carbon nanotubes. Moreover, carbon nanotube coated surface (without polymer) was also evaluated for sensor response. Although carbon nanotubes have excellent properties it is not possible to get repeatable and reliable signals without the polymeric layer (data not shown). As a conclusion, through the use of PF-g-PEG and MWCNTs, the amperometric signals of the biosensor was increased by as much as twofold (Fig. 6A).

The influence of some interferences (glucose, urea, ascorbic acid, uric acid and citric acid) was evaluated. These substrates $(0.1 \mathrm{mM})$ were injected in $50 \mathrm{mM}$ phosphate buffer solution ( $\mathrm{pH} 7.0$ ) at - 0.7 V. As shown in Fig. 7, no remarkable responses were obtained for interferents. On the contrary, the sensor showed a great response to ethanol compared to interfering substances. Moreover, substrate selectivity of the constructed biosensor was also evaluated. For this reason, amperometric responses of different alcohols (methanol and 2-propanol) were analyzed. Amperometric response of methanol was accepted as a reference and the biosensor responses of other substances were compared with each other. All these experiments revealed that ethanol content in the beverages can be correctly analyzed using the proposed sensor.

\subsection{Sample application}

In order to investigate the convenience and reliability of the fabricated biosensor, it was tested for ethanol content in commercial beverages. The results obtained from the proposed biosensor were compared with those from the labels provided by the manufacturers. In order to test sample applicability, appropriate amounts of beverages were injected to the reaction medium and amperometric responses of 

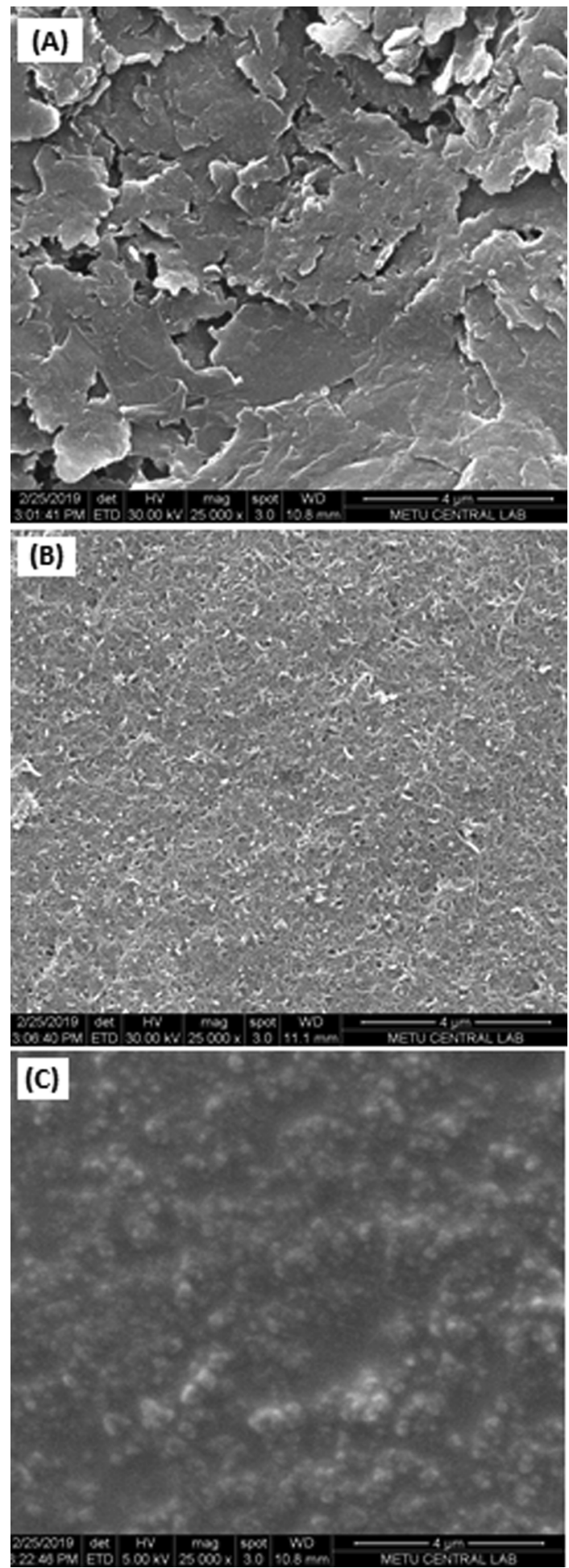

Fig. 5. SEM images of the modified surfaces under the optimized conditions ((A) pristine PF-g-PEG film coated surface (B) MWCNTs/PF-g-PEG electrode and (C)MWCNTs/PF- $g$-PEG/AOx electrode surfaces).

the biosensor were summarized in Table 2. Results show that fabricated biosensor plays an important role in ethanol detection in commercial alcoholic samples.

\section{Conclusion}

A novel poly(ethylene glycol) with fluorene functionality (PEG-FL) macromonomer was synthesized and characterized. PEG-FL
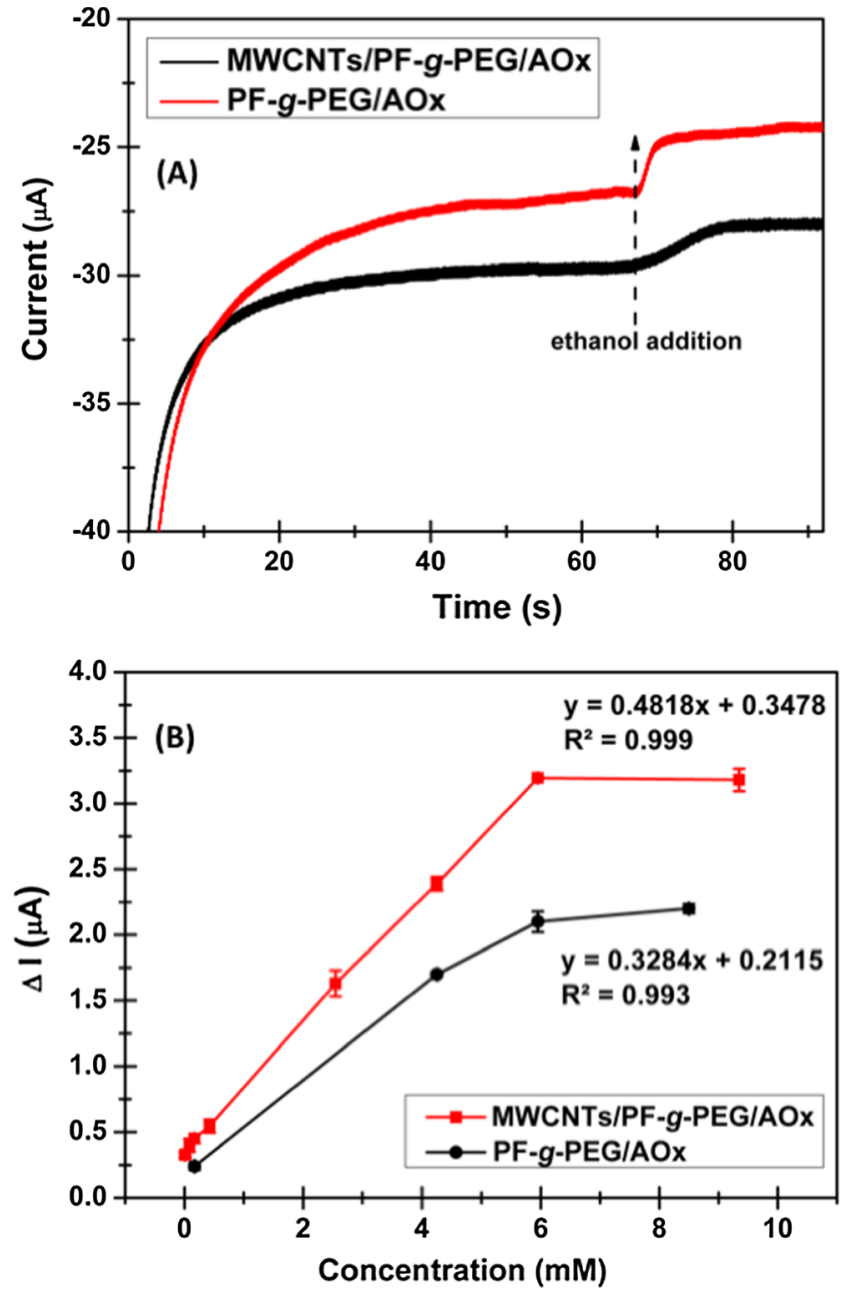

Fig. 6. (A) Comparison of the amperometric responses of the alcohol sensors (for $4.25 \mathrm{mM}$ ethanol) and (B) calibration curve of the biosensors (MWCNTs/ PF-g-PEG/AOx (red line) and PF-g-PEG/AOx (black line) to increasing ethanol concentrations in $50 \mathrm{mM}$ pH 7.0 PBS.

Table 1

Comparison of analytical parameters of the designed biosensor with the previously reported biosensors.

\begin{tabular}{llll}
\hline Biosensor & Linear Range (mM) & $\begin{array}{l}\text { LOD } \\
(\mathrm{mM})\end{array}$ & Reference \\
\hline $\begin{array}{l}\text { Hydrogel/platinum electrode } \\
\quad \text { /AOx }\end{array}$ & $0.02-3.75$ & NR & {$[21]$} \\
$\begin{array}{l}\text { PNR/carbon film electrode } \\
\text { DPP/ Mercury electrode }\end{array}$ & $0-0.8$ & 0.044 & {$[22]$} \\
SPCE/MWCNT/AuNP/PNR/AOx/ & $0.2-2.0$ & 4.3 & {$[23]$} \\
$\quad 0.178-1.0$ & 0.05 & {$[24]$} \\
$\quad$ GPE/GA & Up to 10 & 0.52 & {$[25]$} \\
PMCCH/ABNPs & NR & 0.131 & {$[26]$} \\
MWCNTs/PF-g-PEG/AOX & $0.0085-5.95$ & 0.11 & This work \\
\hline
\end{tabular}

NR: Not reported.

macromonomer was then electrochemically polymerized on the nanotube modified electrode surface in order to use it as an ethanol sensing layer. Such a sensing layer was used for the first time for ethanol sensing in beverages. The results revealed that the biosensor prepared with the combination of PF-g-PEG and MWCNTs showed one of the greatest sensor properties compared to the biosensors prepared with pristine ones. After determining the optimum biosensor, the proposed biosensor was successfully applied for the quantification of alcohol in alcoholic beverages with high accuracy results. Very good kinetic parameters, 


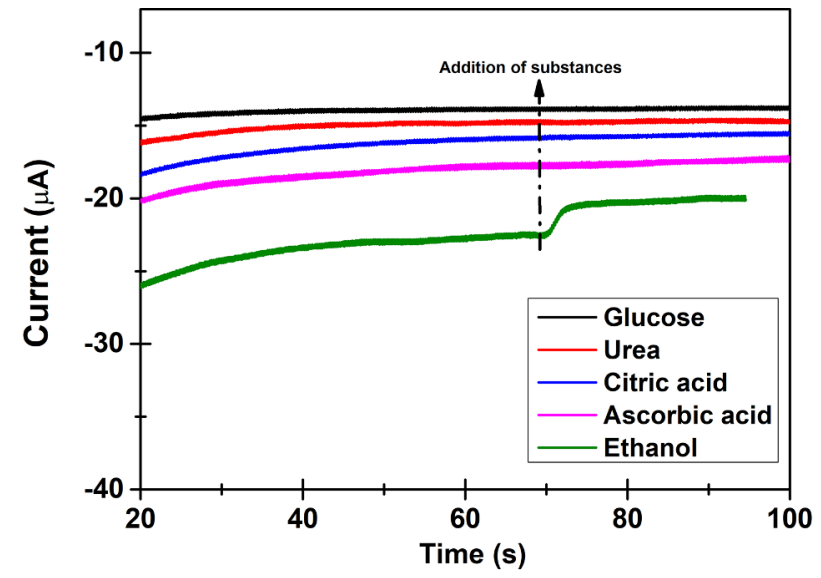

Fig. 7. Interference effect of some substances on the biosensor response.

Table 2

Ethanol detection in beverages using MWCNTs/PF-g-PEG/AOx sensor.

\begin{tabular}{llll}
\hline Sample & Product label (\%) & MWCNTs/PF-g-PEG/AOx (\%) & Percent error (\%) \\
\hline Rum & 37.5 & 35.04 & 6.56 \\
Raki & 45.0 & 42.07 & 6.51 \\
Vodka & 37.5 & 39.25 & 4.66 \\
\hline
\end{tabular}

low LOD value and high dynamic range were obtained from the constructed biosensor. As a result, the excellent performance was owing to the greatest scaffolds for biomolecule arising from the carbon nanotubes (MWCNTs) and polymer (PF- $g$-PEG) electrode.

\section{Declaration of Competing Interest}

The authors declared that there is no conflict of interest.

\section{Acknowledgement}

S. Soylemez is grateful for financial support provided by Ordu University BAP project (Project No. A-1819).

\section{References}

[1] E. Vargas, F. Conzuelo, M.A. Ruiz, S. Campuzano, V.R.-V. Montiel, G.G. Rivera, F.L. Colino, Á.J. Reviejo, J.M. Pingarrón, Automated bioanalyzer based on amperometric enzymatic biosensors for the determination of ethanol in low-alcohol beers, Beverages 3 (2017) 22-38.

[2] A.L. Galant, R.C. Kaufman, J.D. Wilson, Glucose: detection and analysis, Food Chem. 188 (2015) 149-160.

[3] S. Mannino, J. Wang, Electrochemical methods for food and drink analysis, Electroanal. 4 (1992) 835-840.

[4] M.K.L. da Silva, H.C. Vanzela, L.M. Defavari, I. Cesarino, Determination of carbamate pesticide in food using a biosensor based on reduced graphene oxide and acetylcholinesterase enzyme, Sens. Actuators B. Chem. 277 (2018) 555-561.

[5] I.M. Apetrei, C. Apetrei, Amperometric biosensor based on polypyrrole and tyrosinase for the detection of tyramine in food samples, Sens. Actuat. B Chem. 178 (2013) 40-46.

[6] S. Soylemez, F.E. Kanik, S.D. Uzun, S.O. Hacioglu, L. Toppare, Development of an efficient immobilization matrix based on a conducting polymer and functionalized multiwall carbon nanotubes: synthesis and its application to ethanol biosensors, J. Mater. Chem. B 2 (2014) 511-521.

[7] P.D. Thungon, A. Kakoti, L. Ngashangva, P. Goswami, Advances in developing rapid, reliable and portable detection systems for alcohol, Biosens. Bioelectron. 97 (2017) 83-99.

[8] S.R. Chinnadayyala, A. Kakoti, M. Santhosh, P. Goswami, A novel amperometric alcohol biosensor developed in a $3^{\text {rd }}$ generation bioelectrode platform using peroxidase coupled ferrocene activated alcohol oxidase as biorecognition system, Biosens. Bioelectron. 55 (2014) 120-126.

[9] S.R. Chinnadayyala, M. Santhosh, N.K. Singh, P. Goswami, Alcohol oxidase protein mediated in-situ synthesized and stabilized gold nanoparticles for developing amperometric alcohol biosensor, Biosens. Bioelectron. 69 (2015) 155-161.

[10] M. Das, P. Goswami, Direct electrochemistry of alcohol oxidase using multiwalled carbon nanotube as electroactive matrix for biosensor application, Bioelectrochemistry 89 (2013) 19-25.

[11] A. Kausaite-Minkstimiene, V. Mazeiko, A. Ramanaviciene, A. Ramanavicius, Enzymatically synthesized polyaniline layer for extension of linear detection region of amperometric glucose biosensor, Biosens. Bioelectron. 26 (2010) 790-797.

[12] A.H. Parente, E.T.A. Marques, W.M. Azevedo, F.B. Diniz, E.H.M. Melo, J.L. Lima Filho, Glucose biosensor using glucose oxidase immobilized in polyaniline, Appl. Biochem. Biotechnol. 37 (1992) 267-273.

[13] I. Namal, A.C. Ozelcaglayan, Y.A. Udum, L. Toppare, Synthesis and electrochemical characterization of fluorene and benzimidazole containing novel conjugated polymers: effect of alkyl chain length on electrochemical properties, React. Funct. Polym. 49 (2013) 3181-3187.

[14] Z. Kahveci, M.J. Martínez-Tomé, R. Mallavia, C.R. Mateo, Fluorescent biosensor for phosphate determination based on immobilized polyfluorene-liposomal nanoparticles coupled with alkaline phosphatase, ACS Appl. Mater. Interf. 91 (2017) 136-144.

[15] H. Zhang, G. Zhang, J.-K. Xu, Y.-P. Wen, W.-C. Ding, J. Zhang, S.-L. Ming, S.J. Zhen, Electrosynthesis, characterization and optical sensing application of amino acid functionalized polyfluorene, Chinese J. Polym. Sci. 34 (2016) 229-241.

[16] T.C. Bicak, M. Gicevičius, T.C. Gokoglan, G. Yilmaz, A. Ramanavicius, L. Toppare, Y. Yagci, Simultaneous and sequential synthesis of polyaniline-g-poly(ethylene glycol) by combination of oxidative polymerization and CuAAC click chemistry: a water-soluble instant response glucose biosensor material, Macromolecules 50 (2017) 1824-1831.

[17] A. Chen, S. Chatterjee, Nanomaterials based electrochemical sensors for biomedical applications, Chem. Soc. Rev. 42 (2013) 5425-5438.

[18] S. Roy, Z. Gao, Nanostructure-based electrical biosensors, Nano Today 4 (2009) 318-334.

[19] A.J. Bard, L.R. Faulkner, Electrochemical Methods: Fundamentals and Applications, John Wiley, New York, 2000.

[20] J. Wang, Carbon-nanotube based electrochemical biosensors: a review, Electroanalysis 17 (2005) 7-14.

[21] N.G. Patel, S. Meier, K. Comman, G.C. Chemnitius, Screen-printed biosensors using different alcohol oxidases, Sens. Actuat. B Chem. 75 (2001) 101-110.

[22] M.M. Barsan, C.M. Brett, An alcohol oxidase biosensor using PNR redox mediator at carbon film electrodes, Talanta 74 (2008) 1505-1510.

[23] W.H. Chan, A.W. Lee, P.X. Cai, Differential-pulse polarographic microdetermination of ethanol and its application to beer analysis, The Analyst 117 (1992) 1509-1517.

[24] M. Bilgi, E. Ayranci, Development of amperometric biosensors using screen-printed carbon electrodes modified with conducting polymer and nanomaterials for the analysis of ethanol, methanol and their mixtures, J. Electroanal. Chem. 823 (2018) 588-592.

[25] S. Cinti, M. Basso, D. Moscone, F. Arduini, A paper-based nanomodified electrochemical biosensor for ethanol detection in beers, Anal. Chim. Acta 960 (2017) 123-130.

[26] N.C. Kekec, F.E. Kanik, Y.A. Udum, C.G. Hizliates, Y. Ergun, L. Toppare, A novel conducting polymer based platform for ethanol sensing, Sens. Actuat. B. Chem. 193 (2014) 306-314. 